\title{
Emergy Analysis and Sustainability Efficiency Analysis of Different Crop-Based Biodiesel in Life Cycle Perspective
}

\author{
Jingzheng Ren, Alessandro Manzardo, Anna Mazzi, Andrea Fedele, and Antonio Scipioni \\ Department of Industrial Engineering, Quality and Environmental Research Centre (CESQA), University of Padova, \\ Via Marzolo 9, 35131 Padova, Italy \\ Correspondence should be addressed to Antonio Scipioni; scipioni@unipd.it
}

Received 26 March 2013; Accepted 17 April 2013

Academic Editors: A. M. Efstathiou and A. F. Mohedano

Copyright (C) 2013 Jingzheng Ren et al. This is an open access article distributed under the Creative Commons Attribution License, which permits unrestricted use, distribution, and reproduction in any medium, provided the original work is properly cited.

Biodiesel as a promising alternative energy resource has been a hot spot in chemical engineering nowadays, but there is also an argument about the sustainability of biodiesel. In order to analyze the sustainability of biodiesel production systems and select the most sustainable scenario, various kinds of crop-based biodiesel including soybean-, rapeseed-, sunflower-, jatropha- and palmbased biodiesel production options are studied by emergy analysis; soybean-based scenario is recognized as the most sustainable scenario that should be chosen for further study in China. DEA method is used to evaluate the sustainability efficiencies of these options, and the biodiesel production systems based on soybean, sunflower, and palm are considered as DEA efficient, whereas rapeseed-based and jatropha-based scenarios are needed to be improved, and the improved methods have also been specified.

\section{Introduction}

With the depletion of resource, the shortage of energy, and the pollution of the environment, renewable and clean energy has gained more and more attentions nowadays. Being crop based, biodiesel that is a renewable fuel and has lower environmental impact has become a growing rapidly industry in the past decades [1]. However, this positive image has changed dramatically in the last few years, due to several reasons: (i) the diversion of large proportions of grains from food to biodiesel production has caused the increase in the food price; (ii) the global ecological performance of biodiesel is worse than that of fossil fuel; (iii) "the fuel versus food" debate $[2,3]$.

Biodiesel can be produced from oilseeds such as soybean, rapeseed, sunflower, palm oil, and jatropha seeds [4]. Different kinds of crop-based biodiesel have different performance on economic, environmental, and social aspects. Economy, environment, and society are the three pillars of sustainability [3]. Therefore, it can be concluded that different crop-based biodiesel have different sustainability. In order to fulfill the concept of sustainable development, selecting the most sustainable crop-based biodiesel is of vital importance.
Several methods or combinations of some of them have been applied to evaluate the sustainability of biofuel in recent years, such as life cycle assessment [11-14], multicriteria decision-making [15-17], ecological footprint [18], and emergy analysis [19-21]. Among these methods, emergy analysis is the most direct and apparent method to identify the sustainability of an industrial system, because the emergy index of sustainability in emergy analysis is a measure of the sustainability of the industrial systems.

Emergy is the available energy of one kind that has been used up directly and indirectly to make a product or service [22]. The use of a common basis (solar equivalent joules, (sej)) permits to account, all the energy contribution to obtain a certain product or service [23]. It is a powerful tool that can measure the real wealth of the work of nature and society and assess public policies aimed at sustainability and fair trade [21]. Although there are some published papers using emergy analysis as tool to measure the feasibility and sustainability of various crops for biodiesel production, these studies are only about the assessment of the sustainability of the crops or one crop-based biodiesel. Therefore, in order to evaluate the sustainability of various crops-based biodiesel comprehensively, using emergy analysis to evaluate 


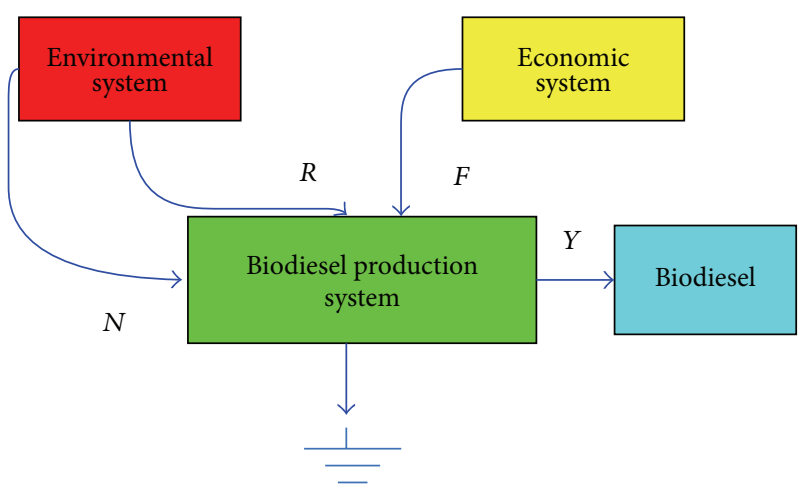

FIGURE 1: Inputs and outputs emergy flows of the biodiesel production system.

the sustainability of various crops-based biodiesel in life cycle perspective is prerequisite.

Emergy analysis is used to study the rapeseed-, sunflower-, soybean-, jatropha-, and palm-based biodiesel, and DEA is used to evaluate the sustainability efficiency in this paper. This paper is organized as follows: Section 2 is emergy analysis; Section 3 is sustainability efficiency analysis, followed by Section 4

\section{Emergy Analysis of Various Crops-Based Biodiesel}

2.1. Emergy Analysis. Emergy analysis has superiority compared with energy analysis or economic analysis, and it cannot only reflect the quality of energy, but also calculate different kinds of energy together on the common unit of joule [5]. Emergy represents solar equivalent joules (sej) to measure natural and economic resources [6]. Solar emergy is usually measured in solar emergy joules (sej), and solar transformity is expressed as solar emergy joules per joule of product $(\mathrm{sej} / \mathrm{J})$. When an item is expressed in units different than joules, for instance grams, then the quality factor is energy/mass (sej/g). The formula for the calculation of emergy has been shown in (1).

The inputs and outputs of emergy flows of a system are shown in Figure 1 and the emergy indices and corresponding calculated methodology used in this paper are shown in Table 1.

Total emergy assigned to the output is called emergy yield $(Y)$, and it is the sum of renewable environmental resources $(R)$, nonrenewable environmental resources $(N)$ and purchased feedback flows of goods and human services from the economy $(F)$. Several other indicators such as transformity (Tr), emergy yield ratio (EYR), emergy investment ratio (EIR), environmental loading ratio (ELR) and environmental sustainability index (ESI) have been used to evaluate the global performance of the systems.

The emergy yield ratio (EYR) provides insight into the net benefit of the various production processes to society, it can be used to measure the ability of the process to rely on local resources, and it does not make any difference local and imported (purchased or "invested") emergy flows [24]. The environmental loading ratio (ELR) can provide additional information to EYR, it expresses the use of environmental services by a system and reflects the impact on environmental stress [25]. Environmental investment ratio (EIR) shows the relation between the emergy of the economic inputs with those provided by the environment, renewable or not [23]. Emergy index of sustainability (EIS) is an aggregate measure of yield and environmental loading, that is, a sustainability function for a given process (or economy) under study [24].

$$
\text { Emergy }=\text { available energy of item } \times \text { transformity. }
$$

2.2. Emergetic Ternary Diagram. Emergetic ternary diagram, including resource flow lines, sensitivity lines, and sustainability line, has been developed by Almeida et al. [26] (Figure 2). With the emergetic ternary diagram, the sustainability of different options can be compared graphically.

Resource flow lines are ternary combinations represented by points within the triangle, the relative proportions of the elements being given by the lengths of the perpendiculars from the given point to the side of the triangle opposite the appropriate element. A resource flow line with the proportions of $R, N, F 0.05,0.93$, and 0.02 respectively, is shown in Figure 4.

Sustainability line is a line which indicates the sustainability index, and it departs from the $N$ apex in the direction of the $R F$ side allowing the division of the triangle into sustainability areas. The sustainability lines with the emergy index of sustainability $0.06,0.6,1.2$, and 1.8 , respectively, are shown in Figure 3. Each system on the same sustainability line has the same emergy index of sustainability, and the nearer the line to $R$ apex, the bigger the emergy index of sustainability. The direction in which the system of the emergy index of sustainability will be bigger is called sustainable development orientation.

Sensitivity line is the line that follows the variation of a given resource flux $(R, N$, or $F)$, and any points along the line represent a condition in which the other two fluxes remain in the same initial proportion [23]. A sensitive line in which the ratio of $R$ and $N$ has the value of 0.25 is shown in Figure 3:

$$
\begin{gathered}
\mathrm{ESI}=\frac{\mathrm{EYR}}{\mathrm{ELR}}=\frac{(R+N+F) / F}{(N+F) / R}, \\
R+N+F=100 \%, \\
\mathrm{ESI}=\frac{1-F-N}{F^{2}+F \times N} .
\end{gathered}
$$

On the basis of (2), $R$ and $N$ can be formulated by ESI and $F$ in (3):

$$
\begin{gathered}
R=\frac{\mathrm{ESI} \times F}{1+\mathrm{ESI} \times F}, \\
N=\frac{1}{1+\mathrm{ESI} \times F}-F .
\end{gathered}
$$

$N$ is always positive and should satisfy (4).

$$
\frac{1}{1+\mathrm{ESI} \times F}-F \geq 0 \text {. }
$$


TABLE 1: Emergy indices and corresponding calculated methodology used in this paper.

\begin{tabular}{lcl}
\hline Name (abbreviation) & Formula & Note \\
\hline Renewable environmental resources & $R$ & Renewable resources provided by the environment \\
Nonrenewable environmental resources & $N$ & Nonrenewable resource \\
Economic inputs & $F$ & The purchased emergy \\
$\begin{array}{l}\text { Product (mass or energy) } \\
\text { Yield }\end{array}$ & $P$ & The mass or energy of the product \\
Transformity & $\mathrm{Tr}=Y / P$ & The ratio of the total emergy inputs to the mass or energy of the product \\
Emergy yield ratio & $\mathrm{EYR}=Y / F$ & The ratio of the output emergy to the purchased emergy \\
Environmental load ratio & $\mathrm{ELR}=(F+N) / R$ & $\begin{array}{l}\text { The ratio of nonrenewable emergy plus the purchased emergy to the renewable } \\
\text { environmental emergy }\end{array}$ \\
Environmental investment ratio & EIR $=F /(R+N)$ & $\begin{array}{l}\text { The ratio of the purchased emergy to the renewable environmental emergy plus } \\
\text { the nonrenewable emergy }\end{array}$ \\
Emergy index of sustainability & ESI $=\mathrm{EYR} / \mathrm{ELR}$ & The ratio of the emergy yield ratio to the environmental load ratio \\
\hline
\end{tabular}

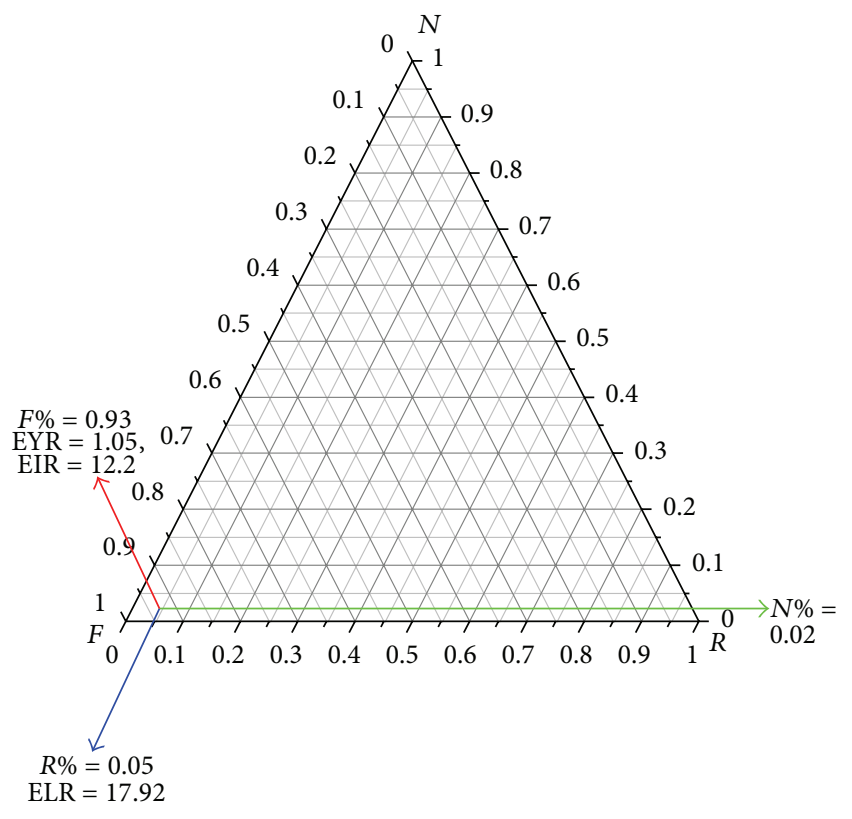

FIGURE 2: Resource flow lines in the emergetic ternary diagram.

Therefore, ESI is fixed, $F$ should satisfy (5), and the maximal proportion of economic inputs is a certain value:

$$
F \leq \frac{\sqrt{1+4 \mathrm{ESI}}-1}{2 \mathrm{ESI}} .
$$

For instance, if ESI $=0.06$, the maximal proportion of economic inputs cannot exceed $94.63 \%$ in order to satisfy the sustainable target.

When $F$ is fixed, ESI should satisfy (6). It means that when the proportion of $F$ equals $94.63 \%$, the maximal Emergy sustainable index is 0.06 :

$$
\mathrm{ESI} \leq \frac{1-F}{F^{2}}
$$

When ESI $<1$, products and process are not sustainable in a long term, when $1<\mathrm{ESI}<5$ the products or processes

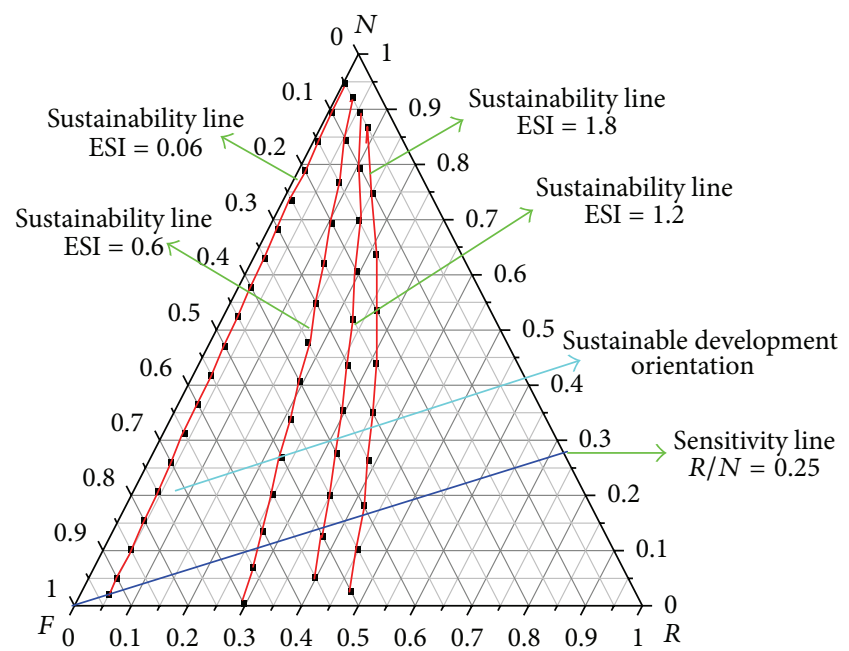

FIGURE 3: Sustainability line in emergetic ternary diagram.

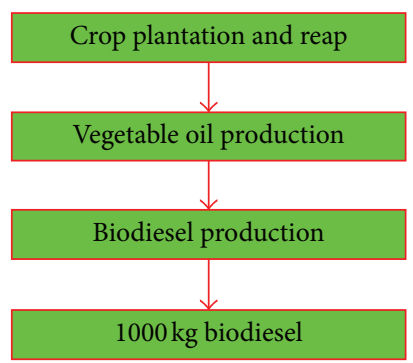

FIGURE 4: The system boundary of the biodiesel production system based on life cycle prespective.

may have a sustainable contribution to the economy for medium periods, and when ESI $>5$ they can be recognized as sustainable in a long term, but if ESI $>10$, the processes are underdeveloped [23].

Based on (5), it can be deduced that the proportion of purchased emergy is: (i) more than $61.80 \%$, the process is not sustainable in a long term, (ii) between $35.83 \%$ and $61.80 \%$, the processes may have a sustainable contribution to the 
economy for medium periods, (iii) lower than $35.83 \%$, it is sustainable in a long term, nevertheless the higher ESI value does not meant the process with better sustainability, and (iv) below $27.02 \%$, the whole system is underdeveloped.

2.3. Function Unit and Boundary of the System. The hypothetical systems for biodiesel production are located in China, and the statistical data are based on the average level of China. The functional unit in this study is $1000 \mathrm{~kg}$ biodiesel and the system boundary is shown in Figure 4; the latter consists of crop plantation and reap, vegetable oil production, and biodiesel production.

2.4. Emergy Analysis of Biodiesel. Five kinds of crop-based biodiesel options including soybean-, rapeseed-, sunflower, palm-and jatropha-based options were studied with emergy analysis, and the alkali-catalyzed process is used to produce biodiesel in the current conditions of China. The emergy of each item can be calculated by (1). The available energy of each item has been calculated in three ways: (i) calculation with the published works, (ii) estimation with the known information, and (iii) statistics. Some of the data in the references have been adjusted according to the suggestions of technical staff of farm science station and engineers of crop oil factories and biodiesel factories.

The emergy analysis of $1000 \mathrm{~kg}$ soybean-based biodiesel has been taken as an example to show how to obtain the available energy of each item. With the survey and the data provided by Yang et al. [5], Tsoutsos et al. [27], and Zhang et al. [28], it can be deduced that $1 \mathrm{~kg}$ soybean oil needs $5.88 \mathrm{~kg}$ soybean, $1 \mathrm{~kg}$ soybean-based biodiesel needs $1.0068 \mathrm{~kg}$ soybean oil, and the yield of soybean is $2540 \mathrm{~kg} / \mathrm{ha}$; therefore, $23304.59 \mathrm{~m}^{2}$ of crop land is needed for producing $1000 \mathrm{~kg}$ soybean-based biodiesel.

The emergy flow diagram of soybean-based biodiesel production system has been shown in Figure 5. Then, the available energy of sunlight, rain, wind, and topsoil loss land can be calculated as shown in Table 2, then with the transformity of each item and (1), the emergy of each item in soybean-based biodiesel system can be obtained, as shown in Table 3.

Similarly, with the survey and the data provided by [2733], the emergy analysis tables of rapeseed-based, sunflowerbased, palm-based, and jatropha-based biodiesel have been shown in Tables 4, 5, 6, and 7, respectively. The emergy indices of various crop-based biodiesel have been shown in Table 8 .

The emergy indices of sustainability of all the crop-based biodiesel studied in this paper are lower than 1 and approach 0 ; it means that these scenarios for biodiesel production are not sustainable in a long term.

The transformities of soybean-based, rapeseed-based, sunflower-based, palm-based, and jatropha-based biodiesel productions are calculated to be $9.85 E+12 \mathrm{sej} / \mathrm{kg}, 9.18 E+$ $12 \mathrm{sej} / \mathrm{kg}, 6.40 E+12 \mathrm{sej} / \mathrm{kg}, 5.83 E+12 \mathrm{sej} / \mathrm{kg}, 1.61 E+13 \mathrm{sej} / \mathrm{kg}$, respectively and palm-based biodiesel is the most emergysaving option, and jatropha is the least.

The sequence of the emergy yield ratios from the biggest to the smallest is soybean, sunflower, rapeseed, palm, and jatropha, to some extent, it indicates that this index can

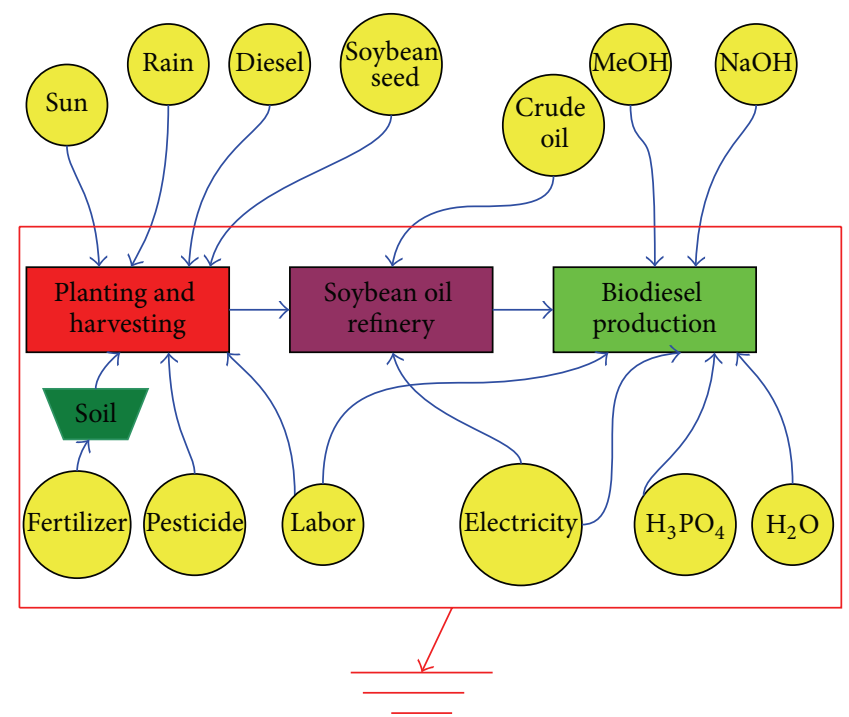

FIGURE 5: Emergy flow diagram of soybean-based biodiesel production system.

represent the proportion of the economic inputs, the smaller the index, the more the system depends on purchased inputs.

The sequence of the environment load ratio from the biggest to the smallest is jatropha, palm, rapeseed, sunflower, and soybean, and it means that soybean-based biodiesel has the best environmental performance. On the contrary, jatropha-based biodiesel has the worst environmental performance. And the sequence of environmental investment ratio is the same as sequence of the environment load ratio, and it denotes that the economic inputs in jatropha-based biodiesel system occupies a higher proportion in the total solar emjoules than the other four, jatropha-based biodiesel system dependents on the purchased inputs significantly.

The solar emjoules of each crop-based biodiesel system is shown in Figure 6. It is apparent that economic inputs occupy a very high proportion in each system, and palmbased biodiesel consumes the least solar energy when taking palm seeds as feedstock to produce biodiesel. It could also be concluded that the total consumed emergy for various cropbased biodiesel depend on the purchased inputs significantly.

The resource flow lines of various crops based biodiesel in the emergetic ternary diagram are shown in Figure 7. The sustainability sequence of the five kinds of biodiesel production systems from the best to the worst is palm, rapeseed, sunflower, soybean and jatropha. The biodiesel based on palm-based system has been recognized as the most sustainable, and the sustainability of jatropha-based system is the worst.

In order to analyze the emergy indices comprehensively, a multicriteria representation has been proposed, as shown in Figure 8. ESI and EYI are the-larger-the-better criteria, and the-smaller-the-better criteria such as EIR and ELR are transformed into the-larger-the-better criteria in reciprocal way. The sequence of the comprehensive performance of the systems from the best to the worst is soybean-, sunflower-, rapeseed-, palm-, and jatropha-based biodiesel option. This multi-criteria representation has neglected the comparison of 
TABLE 2: Calculation of the available energy of each item for soybean-based biodiesel.

\begin{tabular}{|c|c|}
\hline \multirow{5}{*}{ Sunlight } & Area $=23304.59 \mathrm{~m}^{2}$ \\
\hline & Insolation $=4.77 E+9 \mathrm{~J} / \mathrm{m}^{2} / \mathrm{yr}$ \\
\hline & Albedo $=0.3$ \\
\hline & $T=0.35 \mathrm{yr}$ \\
\hline & Energy $(J)=($ Area $) \times($ Insolation $) \times(1-$ Albedo $) \times T=1.17 E+13 \mathrm{~J}$ \\
\hline \multirow{7}{*}{ Rain geopotential } & Area $=23304.59 \mathrm{~m}^{2}$ \\
\hline & Rainfall $=0.3 \mathrm{~m}$ \\
\hline & Rain-off rate $=0.20$ \\
\hline & Average elevation $=100 \mathrm{~m}$ \\
\hline & Density $=1000 \mathrm{~kg} / \mathrm{m}^{3}$ \\
\hline & Gravity $=9.80 \mathrm{~s} / \mathrm{m}^{2}$ \\
\hline & Energy $(\mathrm{J})=($ Area $) \times($ Rainfall $) \times($ Rainoff rate $) \times($ Average elevation $) \times$ Density $\times$ Gravity $=1.37 E+09 \mathrm{~J}$ \\
\hline \multirow{5}{*}{$\begin{array}{l}\text { Rain chemical } \\
\text { potential }\end{array}$} & Area $=23304.59 \mathrm{~m}^{2}$ \\
\hline & Rainfall $=0.3 \mathrm{~m}$ \\
\hline & Density $=1000 \mathrm{~kg} / \mathrm{m}^{3}$ \\
\hline & Gibbs free energy $=1940 \mathrm{~J} / \mathrm{kg}$ \\
\hline & Energy $(J)=($ Area $) \times($ Rainfall $) \times($ Density $) \times($ Gibbs free energy $)=1.36 E+10 J$ \\
\hline \multirow{7}{*}{ Wind } & Area $=23304.59 \mathrm{~m}^{2}$ \\
\hline & Air density $=1.23 \mathrm{~kg} / \mathrm{m}^{3}$ \\
\hline & Drag coefficient $=0.001$ \\
\hline & Average annual wind velocity $=2.4 \mathrm{~m} / \mathrm{s}$ \\
\hline & Geostrophic wind $=10$ Average annual wind velocity $/ 6=4.17 \mathrm{~m} / \mathrm{s}$ \\
\hline & $T=0.35 \mathrm{yr}$ \\
\hline & Energy $(J)=($ Area $) \times($ Air Density $) \times($ Drag coefficient $) \times(\text { Geostrophic wind })^{3} \times(3600 \times 24 \times 365 \times T)=2.29 E+10 \mathrm{~J}$ \\
\hline \multirow{3}{*}{ Topsoil loss } & Area $=23304.59 \mathrm{~m}^{2}$ \\
\hline & Topsoil loss energy $=1.32 E+09 \mathrm{~J} / \mathrm{hm}^{2}$ \\
\hline & Energy $(J)=($ Area $) \times$ Topsoil loss energy $=3.08 E+09 \mathrm{~J}$ \\
\hline
\end{tabular}

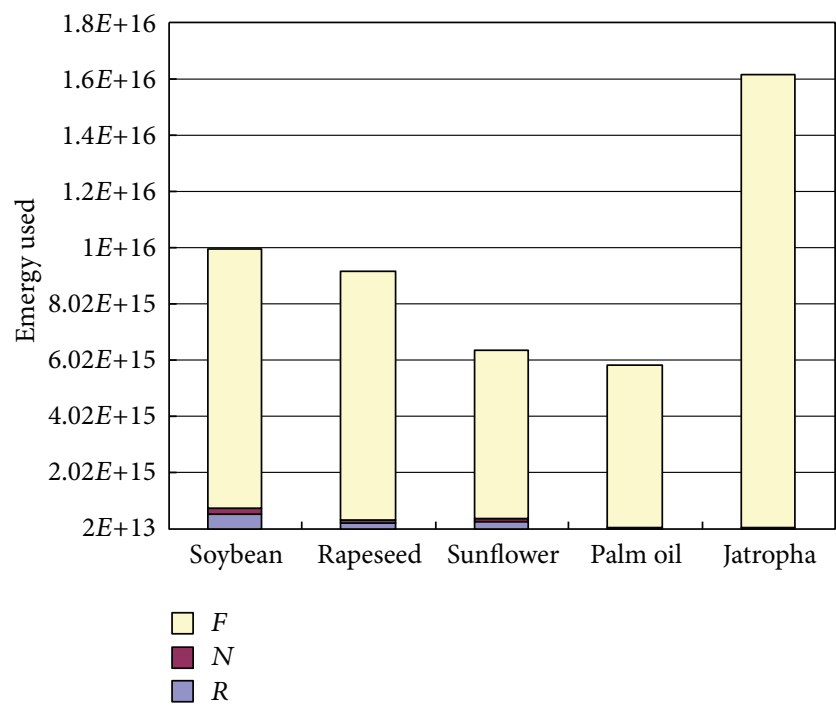

Figure 6: The solar emjoules of each crop-based biodiesel system.

transformities and the importance (weights) of the emergy indices; Section 3 proposes a novel methodology to analyze

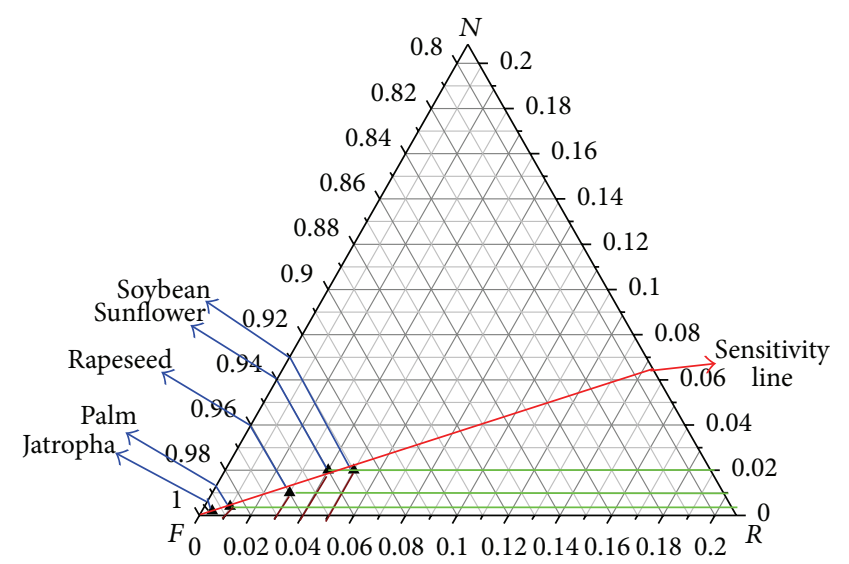

FIGURE 7: Resource flow lines of various crops-based biodiesel in the emergetic ternary diagram.

the integrated performance of the emergy indices comprehensively.

\section{Sustainability Efficiency Analysis}

3.1. Data Envelopment Analysis. The data envelopment was developed by Charnes et al. in 1978 [34], which was widely 
TABLE 3: Emergy analysis table for soybean-based biodiesel.

\begin{tabular}{|c|c|c|c|c|c|c|c|}
\hline Stage & Type & Item & Data & Reference & Transformity (sej/unit) & Reference & Solar emergy (sej) \\
\hline \multirow{13}{*}{ Plantation and reap } & \multirow{4}{*}{$R$} & Sunlight $(\mathrm{J})$ & $1.17 E+13$ & Calculated & $1.00 E+00$ & {$[5]$} & $1.17 E+13$ \\
\hline & & Rain geopotential (J) & $1.37 E+09$ & Calculated & $4.70 E+04$ & {$[5]$} & $6.44 E+13$ \\
\hline & & Rain chemical potential $(\mathrm{J})$ & $1.36 E+10$ & Calculated & $3.05 E+04$ & {$[5]$} & $4.15 E+14$ \\
\hline & & Wind $(\mathrm{J})$ & $2.29 E+10$ & Calculated & $1.50 E+03$ & {$[6]$} & $3.44 E+13$ \\
\hline & $N$ & Topsoil loss & $3.08 E+09$ & Calculated & $7.40 E+04$ & {$[5]$} & $2.28 E+14$ \\
\hline & \multirow{8}{*}{$F$} & Water $(\mathrm{kg})$ & 5033790 & Statistics & $4.65 E+08$ & {$[6]$} & $2.34 E+15$ \\
\hline & & Nitrogen $(\mathrm{kg})$ & 93.22 & Statistics & $2.40 E+13$ & {$[5]$} & $2.24 E+15$ \\
\hline & & Biocide trifluralin $(\mathrm{kg})$ & 2.33 & Statistics & $1.48 E+13$ & [5] & $3.45 E+13$ \\
\hline & & Pesticide pirimicarb $(\mathrm{kg})$ & 2.33 & Statistics & $1.48 E+13$ & {$[5]$} & $3.45 E+13$ \\
\hline & & Pesticides dicofol (kg) & 1.17 & Statistics & $1.48 E+13$ & {$[5]$} & $1.73 E+13$ \\
\hline & & Diesel $(\mathrm{kg})$ & 212.5 & Estimated & $3.04 E+12$ & {$[7]$} & $6.46 E+14$ \\
\hline & & Human labor (h) & 200 & Estimated & $1.1 E+12$ & {$[5]$} & $2.2 E+14$ \\
\hline & & Soybean seed (\$) & 108.56 & Statistics & $1.18 E+13$ & {$[8]$} & $1.28 E+15$ \\
\hline \multirow{2}{*}{ Soybean oil production } & \multirow{2}{*}{ n $F$} & Crude oil (J) & $1.05 E+10 \mathrm{~J}$ & Statistics & $5.4 E+04$ & [9] & $5.67 E+14$ \\
\hline & & Electricity (J) & $1245.86 E+06$ & Statistics & $3.36 E+05$ & {$[8]$} & $4.19 E+14$ \\
\hline \multirow{6}{*}{ Biodiesel production } & \multirow{6}{*}{$F$} & $\mathrm{MeOH}(\mathrm{kg})$ & 217.90 & Statistics & $1.76 E+12$ & {$[8]$} & $3.84 E+14$ \\
\hline & & $\mathrm{NaOH}(\mathrm{kg})$ & 8.16 & Statistics & $6.38 E+12$ & {$[8]$} & $5.21 E+13$ \\
\hline & & $\mathrm{H}_{2} \mathrm{O}(\mathrm{kg})$ & 1018.41 & Statistics & $4.65 E+08$ & {$[6]$} & $4.74 E+11$ \\
\hline & & $\mathrm{H}_{3} \mathrm{PO}_{4}(\mathrm{~kg})$ & 6.06 & Statistics & $2.65 E+12$ & [9] & $1.61 E+13$ \\
\hline & & Electricity (J) & $251.69 E+06$ & Statistics & $3.36 E+05$ & {$[8]$} & $8.46 E+13$ \\
\hline & & Human labor (h) & 800 & Estimated & $1.1 E+12$ & {$[5]$} & $8.8 E+14$ \\
\hline
\end{tabular}

TABLE 4: Emergy analysis table for rapeseed-based biodiesel.

\begin{tabular}{|c|c|c|c|c|c|c|c|}
\hline Stage & Type & Item & Data & Reference & Transformity (sej/unit) & Reference & Solar emergy (sej) \\
\hline \multirow{12}{*}{ Plantation and reap } & \multirow{4}{*}{$R$} & Sunlight (J) & $0.52 E+13$ & Calculated & $1.00 E+00$ & [5] & $0.52 E+13$ \\
\hline & & Rain geopotential (J) & $0.61 E+09$ & Calculated & $4.70 E+04$ & {$[5]$} & $2.87 E+13$ \\
\hline & & Rain chemical potential (J) & $0.60 E+10$ & Calculated & $3.05 E+04$ & [5] & $1.83 E+14$ \\
\hline & & Wind $(J)$ & $1.01 E+10$ & Calculated & $1.50 E+03$ & [6] & $1.52 E+13$ \\
\hline & $N$ & Topsoil loss & $1.36 E+09$ & Calculated & $7.40 E+04$ & {$[5]$} & $1.01 E+14$ \\
\hline & \multirow{7}{*}{$F$} & Water (kg) & 556010 & Statistics & $4.65 E+08$ & [6] & $0.26 E+15$ \\
\hline & & Nitrogen (kg) & 236.82 & Statistics & $2.40 E+13$ & [5] & $5.69 E+15$ \\
\hline & & Biocide trifluralin (kg) & 1.03 & Statistics & $1.48 E+13$ & [5] & $1.53 E+13$ \\
\hline & & Pesticide pirimicarb $(\mathrm{kg})$ & 1.03 & Statistics & $1.48 E+13$ & [5] & $1.53 E+13$ \\
\hline & & Diesel $(\mathrm{kg})$ & 127.5 & Estimated & $3.04 E+12$ & {$[5]$} & $3.88 E+14$ \\
\hline & & Human labor (h) & 200 & Estimated & $1.1 E+12$ & {$[5]$} & $2.2 E+14$ \\
\hline & & Rapeseed seed (\$) & 24.32 & Statistics & $1.18 E+13$ & {$[8]$} & $0.29 E+15$ \\
\hline \multirow{2}{*}{ Rapeseed oil production } & \multirow{2}{*}{$F$} & Crude oil (J) & $0.45 E+10 \mathrm{~J}$ & Statistics & 5.4 & [9] & $2.43 E+14$ \\
\hline & & Electricity $(\mathrm{J})$ & $939.66 E+06$ & Statistics & $3.36 E+05$ & [8] & $3.14 E+14$ \\
\hline \multirow{6}{*}{ Biodiesel production } & \multirow{6}{*}{$F$} & $\mathrm{MeOH}(\mathrm{kg})$ & 216.23 & Statistics & $1.76 E+12$ & {$[8]$} & $3.81 E+14$ \\
\hline & & $\mathrm{NaOH}(\mathrm{kg})$ & 8.03 & Statistics & $6.38 E+12$ & {$[8]$} & $5.13 E+13$ \\
\hline & & $\mathrm{H}_{2} \mathrm{O}(\mathrm{kg})$ & 1019.36 & Statistics & $4.65 E+08$ & [6] & $4.74 E+11$ \\
\hline & & $\mathrm{H}_{3} \mathrm{PO}_{4}(\mathrm{~kg})$ & 6.28 & Statistics & $2.65 E+12$ & [9] & $1.81 E+13$ \\
\hline & & Electricity (J) & $2.36 E+08$ & Statistics & $3.36 E+05$ & {$[8]$} & $7.94 E+13$ \\
\hline & & Human labor (h) & 800 & Estimated & $1.1 E+12$ & {$[5]$} & $8.8 E+14$ \\
\hline
\end{tabular}


TABLE 5: Emergy analysis table for sunflower-based biodiesel.

\begin{tabular}{|c|c|c|c|c|c|c|c|}
\hline Stage & Type & Item & Data & Reference & Transformity (sej/unit) & Reference & Solar emergy (sej) \\
\hline \multirow{11}{*}{ Plantation and reap } & \multirow{4}{*}{$R$} & Sunlight (J) & $0.60 E+13$ & Calculated & $1.00 E+00$ & [5] & $0.60 E+13$ \\
\hline & & Rain geopotential $(\mathrm{J})$ & $0.70 E+09$ & Calculated & $4.70 E+04$ & [5] & $3.29 E+13$ \\
\hline & & Rain chemical potential (J) & $0.70 E+10$ & Calculated & $3.05 E+04$ & [5] & $2.14 E+14$ \\
\hline & & Wind $(J)$ & $1.18 E+10$ & Calculated & $1.50 E+03$ & {$[6]$} & $1.77 E+13$ \\
\hline & $N$ & Topsoil loss & $1.95 E+09$ & Calculated & $7.40 E+04$ & {$[5]$} & $1.44 E+14$ \\
\hline & \multirow{6}{*}{$F$} & Water (kg) & $1.30 E+06$ & Statistics & $4.65 E+08$ & {$[6]$} & $0.61 E+15$ \\
\hline & & Nitrogen (kg) & 83.89 & Statistics & $2.40 E+13$ & {$[5]$} & $2.02 E+15$ \\
\hline & & Biocide trifluralin (kg) & 1.20 & Statistics & $1.48 E+13$ & {$[5]$} & $1.78 E+13$ \\
\hline & & Diesel (kg) & 326.3 & Estimated & $3.04 E+12$ & {$[5]$} & $9.93 E+14$ \\
\hline & & Human labor (h) & 200 & Estimated & $1.1 E+12$ & [5] & $2.20 E+14$ \\
\hline & & Sunflower seed (\$) & 120.30 & Statistics & $1.18 E+13$ & {$[8]$} & $1.43 E+15$ \\
\hline \multirow{2}{*}{ Sunflower oil production } & \multirow{2}{*}{ n $F$} & Crude oil (J) & $0.71 E+10$ & Statistics & $5.4 E+04$ & [10] & $3.83 E+14$ \\
\hline & & Electricity $(\mathrm{J})$ & $9.17 E+08$ & Statistics & $3.36 E+05$ & {$[8]$} & $3.08 E+14$ \\
\hline \multirow{6}{*}{ Biodiesel production } & \multirow{6}{*}{$F$} & $\mathrm{MeOH}(\mathrm{kg})$ & 217.76 & Statistics & $1.76 E+12$ & {$[8]$} & $3.84 E+14$ \\
\hline & & $\mathrm{NaOH}(\mathrm{kg})$ & 8.03 & Statistics & $6.38 E+12$ & {$[8]$} & $5.13 E+13$ \\
\hline & & $\mathrm{H}_{2} \mathrm{O}(\mathrm{kg})$ & 1018.34 & Statistics & $4.65 E+08$ & {$[6]$} & $4.74 E+11$ \\
\hline & & $\mathrm{H}_{3} \mathrm{PO}_{4}(\mathrm{~kg})$ & 6.23 & Statistics & $2.65 E+12$ & [9] & $1.80 E+13$ \\
\hline & & Electricity (J) & $215.72 E+06$ & Statistics & $3.36 E+05$ & {$[8]$} & $7.25 E+13$ \\
\hline & & Human labor (h) & 800 & Estimated & $1.1 E+12$ & {$[5]$} & $8.8 E+14$ \\
\hline
\end{tabular}

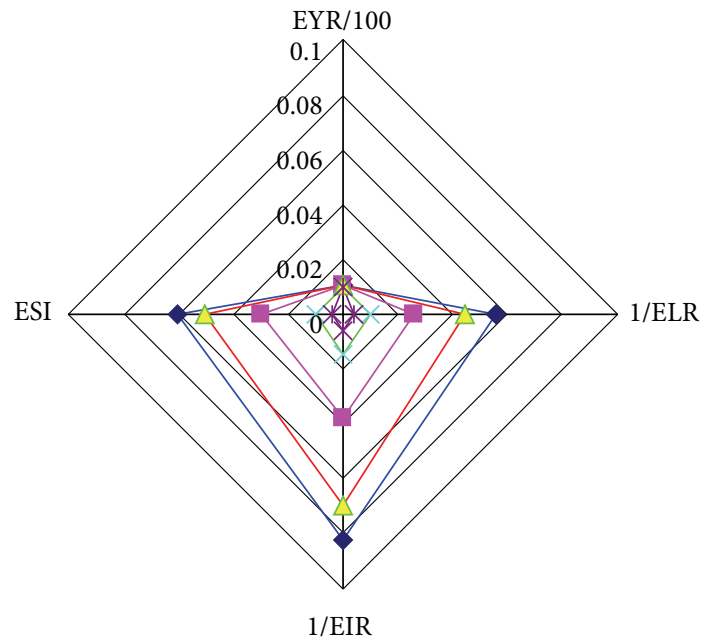

- Soybean
- Rapeseed
- Sunflower

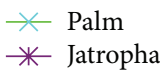

FIGURE 8: Multicriteria representations of various biodiesel production options.

used for assessing the alternatives with the inputs and outputs of these systems [35]. Each alternative can be considered as a system which is also called decision-making unit (DMU), as shown in Figure 9.

The meaning of the symbols in Figure 9 has been defined as follows:

$$
\begin{aligned}
& r: 1,2, \ldots, m \text { inputs, } \\
& i: 1,2, \ldots, p \text { outputs, }
\end{aligned}
$$

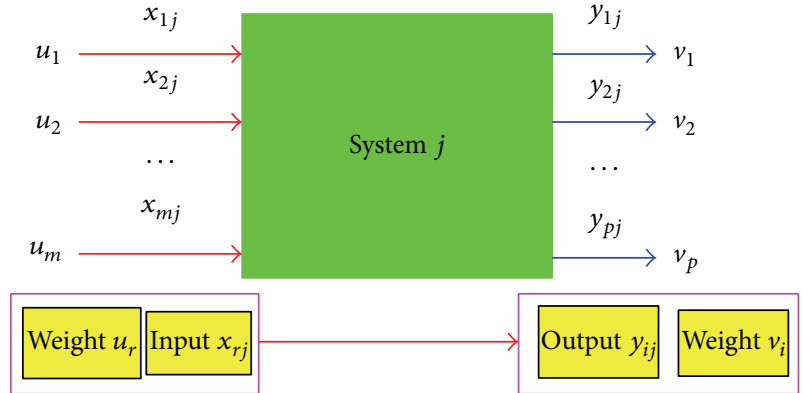

FIGURE 9: Structure of DEA assessment system.

$$
\begin{aligned}
& j: 1,2, \ldots, t \text { system } j, \\
& x_{r j}: \text { the amount of input } r \text { for unit } j, \\
& y_{i j}: \text { the amount of input } i \text { for unit } j, \\
& u_{r}: \text { the weighting of input } r, \\
& v_{i}: \text { the weighting of output } i .
\end{aligned}
$$

The efficiency of a decision-making unit $j$ can be formulated by the ratio of weighted sum of outputs to weighted sum of inputs [36], as shown in (7):

$$
h_{j}=\frac{\sum_{i=1}^{p} v_{i} y_{i j}}{\sum_{r=1}^{m} u_{r} x_{r j}}
$$

Weights of the inputs and outputs can be determined by the decision makers/stakeholders, but that is a subjective way; a model can achieve that in an objective way. The model is to maximize the efficiency of the target system with the 
constraints of the efficiencies of the other systems $\leq 1$ [37]. The efficiency of the target system $j_{0}$ can be calculated by solving the programming problem as follows:

$$
\max h_{0}=\frac{\sum_{i=1}^{p} v_{i} y_{i j_{0}}}{\sum_{r=1}^{m} u_{r} x_{r j_{0}}}
$$

subject to

$$
\begin{gathered}
\frac{\sum_{i=1}^{p} v_{i} y_{i j}}{\sum_{r=1}^{m} u_{r} x_{r j}} \leq 1 \quad(j=1,2, \ldots, t) \\
u_{r} \geq \varepsilon \quad r=1,2, \ldots, m \\
v_{i} \geq \varepsilon \quad i=1,2, \ldots, p,
\end{gathered}
$$

where $\varepsilon$ is a nonarchimedean construct.

The constraints (9) indicate that the upper bound of the efficiency of the DMU is $100 \%$, namely, the efficiency cannot exceed 1.

The model can be transformed into matrix form:

$$
\begin{gathered}
\max h_{0}=\frac{v^{T} y_{0}}{u^{T} x_{0}}, \\
\frac{v^{T} y_{j}}{u^{T} x_{j}} \leq 1, \\
u \geq \varepsilon, \quad v \geq \varepsilon,
\end{gathered}
$$

where $u=\left(u_{1}, u_{2}, \ldots, u_{m}\right)^{T}, v=\left(v_{1}, v_{2}, \ldots, v_{p}\right)^{T}, x_{j}=$ $\left(x_{1 j}, x_{2 j}, \ldots, x_{m j}\right)^{T}, y_{j}=\left(y_{1 j}, y_{2 j}, \ldots, y_{p j}\right)^{T}, x_{0}=\left(x_{1 j_{0}}\right.$, $\left.x_{2 j_{0}}, \ldots, x_{m j_{0}}\right)^{T}, y_{0}=\left(y_{1 j_{0}}, y_{2 j_{0}}, \ldots, y_{p j_{0}}\right)^{T}$.

Based on Charnes-Cooper transformation [38], the equivalent linear programming can be acquired:

$$
\max v^{T} y_{0}
$$

subject to

$$
\begin{gathered}
\sum_{r=1}^{m} u_{r} x_{r j_{0}}=1, \\
\sum_{i=1}^{p} v_{i} y_{i j}-\sum_{r=1}^{m} u_{r} x_{r j} \leq 0 \quad(j=1,2, \ldots, t), \\
u \geq \varepsilon, \quad v \geq \varepsilon
\end{gathered}
$$

Then, the linear programming problem can be transformed into the following form:

$$
\begin{gathered}
\max \left(u^{T}, v^{T}\right)\left(\begin{array}{c}
0 \\
y_{0}
\end{array}\right), \\
v^{T} y_{j}-u^{T} x_{j} \leq 0 \quad(j=1,2, \ldots, t), \\
u \geq \varepsilon, \quad v \geq \varepsilon
\end{gathered}
$$

According to the duality theory of linear programming, it can be transformed into the following form:

$$
\min g-\varepsilon\left(\sum_{r=1}^{m} s_{r}^{+}+\sum_{i=1}^{p} s_{i}^{-}\right)
$$

subject to

$$
\begin{gathered}
\sum_{j=1}^{t} x_{r j} \lambda_{j}+s_{r}^{-}-g x_{r j_{0}}=0, \\
\sum_{j=1}^{t} y_{i j} \lambda_{j}-s_{i}^{+}-y_{i j_{0}}=0, \\
\lambda_{j} \geq 0 \quad(j=1,2, \ldots, t), \\
s_{r}^{-} \geq 0 \quad(r=1,2, \ldots, m), \\
s_{i}^{+} \geq 0 \quad(i=1,2, \ldots, p) .
\end{gathered}
$$

Definition 1. If the optimal value $g=1$, then the decisionmaking unit can be identified as weak DEA effective and vice versa.

Definition 2. If the optimal value $g=1$ and the solution satisfies $s_{r}^{-}=0(r=1,2, \ldots, m), s_{i}^{+}=0(i=1,2, \ldots, p)$, then the decision-making unit can be identified as DEA effective, and vice versa.

Therefore, once the inputs and outputs of the systems for assessment have been obtained, the question whether some system is DEA efficient or not can be answered by solving the linear programming (14) and (15).

3.2. Sustainability Efficiency of Biodiesel Systems. The concept of sustainability has been defined as the ratio of the sum of the weighted outputs to the sum of the weighted inputs, and the inputs comprise transformity, environmental load ratio, and environmental investment ratio, the outputs comprise emergy index of sustainability, emergy yield ratio and product, as shown in (16):

$$
h_{j}=\frac{v_{1} \mathrm{ESI}+v_{2} \mathrm{EYR}+v_{3} P}{u_{1} T r+u_{2} \mathrm{ELR}+u_{3} \mathrm{EIR}}
$$

where $v_{1}, v_{2}$, and $v_{3}$ represent the weights of ESI, EYR, and $P$, respectively; $u_{1}, u_{2}$, and $u_{3}$ represent the weights of Tr, ELR and EIR respectively.

The production of biodiesel can be considered as a system; similarly, the alternatives for biodiesel production can also be considered as decision-making units (DMUs). The inputs of these DMUs comprise transformity (Tr), environmental loading ratio (ELR) and emergy investment ratio (EIR), the outputs include emergy sustainable index (ESI) emergy yield ratio (EYR) and product yield $(P)$. The structure of DEA assessment system for biodiesel production is shown in Figure 10. 
TABLE 6: Emergy analysis table for palm-based biodiesel.

\begin{tabular}{|c|c|c|c|c|c|c|c|}
\hline Stage & Type & Item & Data & Reference & Transformity (sej/unit) & Reference & Solar emergy (sej) \\
\hline \multirow{12}{*}{ Plantation and reap } & \multirow{4}{*}{$R$} & Sunlight $(J)$ & $0.13 E+13$ & Calculated & $1.00 E+00$ & {$[5]$} & $0.13 E+13$ \\
\hline & & Rain geopotential (J) & $0.15 E+09$ & Calculated & $4.70 E+04$ & {$[5]$} & $0.71 E+13$ \\
\hline & & Rain chemical potential (J) & $0.15 E+10$ & Calculated & $3.05 E+04$ & {$[5]$} & $0.46 E+14$ \\
\hline & & Wind $(J)$ & $0.25 E+10$ & Calculated & $1.50 E+03$ & {$[6]$} & $0.38 E+13$ \\
\hline & $N$ & Topsoil loss & $0.33 E+09$ & Calculated & $7.40 E+04$ & {$[5]$} & $2.44 E+13$ \\
\hline & \multirow{7}{*}{$F$} & Nitrogen $(\mathrm{kg})$ & 39.03 & Statistics & $2.40 E+13$ & {$[5]$} & $9.37 E+14$ \\
\hline & & Phosphate (kg) & 8.71 & Statistics & $2.02 E+13$ & {$[5]$} & $1.76 E+14$ \\
\hline & & Potash (kg) & 150.32 & Statistics & $1.74 E+12$ & {$[5]$} & $2.62 E+14$ \\
\hline & & Biocide Paraquat (kg) & 0.26 & Statistics & $1.48 E+13$ & {$[5]$} & $0.32 E+13$ \\
\hline & & Diesel (J) & $6.44 E+08$ & Statistics & $1.11 E+05$ & {$[5]$} & $7.15 E+13$ \\
\hline & & Human labor (h) & 200 & Estimated & $1.1 E+12$ & {$[5]$} & $2.2 E+14$ \\
\hline & & Palm management fee $(\$)$ & 225.56 & Estimated & $1.18 E+13$ & {$[8]$} & $2.66 E+15$ \\
\hline \multirow{2}{*}{ Palm oil production } & \multirow{2}{*}{$F$} & Crude oil $(\mathrm{J})$ & $9.13 E+08$ & Estimated & $5.4 E+04$ & {$[10]$} & $4.93 E+13$ \\
\hline & & Electricity $(\mathrm{J})$ & $2.69 E+08$ & Statistics & $3.36 E+05$ & {$[8]$} & $9.06 E+13$ \\
\hline \multirow{6}{*}{ Biodiesel production } & \multirow{6}{*}{$F$} & $\mathrm{MeOH}(\mathrm{kg})$ & 180 & Statistics & $1.76 E+12$ & {$[8]$} & $3.17 E+14$ \\
\hline & & $\mathrm{NaOH}(\mathrm{kg})$ & 5.86 & Statistics & $6.38 E+12$ & {$[8]$} & $3.74 E+13$ \\
\hline & & $\mathrm{H}_{2} \mathrm{O}(\mathrm{kg})$ & 1500 & Estimated & $4.65 E+08$ & {$[6]$} & $6.98 E+11$ \\
\hline & & $\mathrm{H}_{3} \mathrm{PO}_{4}(\mathrm{~kg})$ & 0.96 & Estimated & $2.65 E+12$ & [9] & $0.28 E+13$ \\
\hline & & Electricity $(J)$ & $1.14 E+08$ & Statistics & $3.36 E+05$ & {$[8]$} & $3.82 E+13$ \\
\hline & & Human labor (h) & 800 & Estimated & $1.1 E+12$ & {$[5]$} & $8.8 E+14$ \\
\hline
\end{tabular}

TABLE 7: Emergy analysis table for jatropha-based biodiesel.

\begin{tabular}{|c|c|c|c|c|c|c|c|}
\hline Stage & Type & Item & Data & Reference & Transformity (sej/unit) & Reference & Solar emergy (sej) \\
\hline \multirow{11}{*}{ Plantation and reap } & \multirow{4}{*}{$R$} & Sunlight $(J)$ & $0.15 E+13$ & Calculated & $1.00 E+00$ & {$[5]$} & $0.15 E+13$ \\
\hline & & Rain geopotential (J) & $0.17 E+09$ & Calculated & $4.70 E+04$ & {$[5]$} & $0.80 E+13$ \\
\hline & & Rain chemical potential (J) & $0.17 E+10$ & Calculated & $3.05 E+04$ & [5] & $0.52 E+14$ \\
\hline & & Wind $(\mathrm{J})$ & $0.28 E+10$ & Calculated & $1.50 E+03$ & {$[6]$} & $0.42 E+13$ \\
\hline & $N$ & Topsoil loss & $0.38 E+09$ & Calculated & $7.40 E+04$ & {$[5]$} & $2.81 E+13$ \\
\hline & \multirow{6}{*}{$F$} & Water $(\mathrm{kg})$ & 10705350 & Statistics & $4.65 E+08$ & {$[6]$} & $4.98 E+15$ \\
\hline & & Nitrogen $(\mathrm{kg})$ & 87 & Statistics & $2.40 E+13$ & [5] & $2.09 E+15$ \\
\hline & & Phosphate (kg) & 174 & Statistics & $2.02 E+13$ & {$[5]$} & $3.51 E+15$ \\
\hline & & Diesel (kg) & 255 & Estimated & $3.04 E+12$ & {$[5]$} & $7.75 E+14$ \\
\hline & & Human labor (h) & 200 & Estimated & $1.1 E+12$ & {$[5]$} & $2.2 E+14$ \\
\hline & & Jatropha management fee (\$) & 225.56 & Estimated & $1.18 E+13$ & [8] & $2.66 E+15$ \\
\hline Jatropha oil production & $F$ & Electricity $(\mathrm{J})$ & $4.91 E+08$ & Statistics & $3.36 E+05$ & {$[8]$} & $1.65 E+14$ \\
\hline \multirow{6}{*}{ Biodiesel production } & \multirow{6}{*}{$F$} & $\mathrm{MeOH}(\mathrm{kg})$ & 391 & Statistics & $1.76 E+12$ & {$[8]$} & $6.88 E+14$ \\
\hline & & $\mathrm{NaOH}(\mathrm{kg})$ & 8 & Statistics & $6.38 E+12$ & {$[8]$} & $5.10 E+13$ \\
\hline & & $\mathrm{H}_{2} \mathrm{O}(\mathrm{kg})$ & 1000 & Estimated & $4.65 E+08$ & {$[6]$} & $4.65 E+11$ \\
\hline & & $\mathrm{H}_{3} \mathrm{PO}_{4}(\mathrm{~kg})$ & 6.84 & Statistics & $2.65 E+12$ & {$[9]$} & $1.81 E+13$ \\
\hline & & Electricity (J) & $3.02 E+07$ & Statistics & $3.36 E+05$ & {$[8]$} & $1.01 E+13$ \\
\hline & & Human labor $(\mathrm{h})$ & 800 & Estimated & $1.1 E+12$ & {$[5]$} & $8.8 E+14$ \\
\hline
\end{tabular}

In order to calculate more conveniently, all the data including inputs and output should be processed in the following ways, as shown in (17):

$$
X_{r j}=\frac{x_{r j}}{\sum_{j=1}^{t} x_{r j} / t} \quad r=1,2, \ldots, m ; j=1,2, \ldots, t
$$

where $X_{r j}$ is the $(j)$ th input or output in the $(r)$ th DMU; $t$ is the total number of the DMUs.

Based on the data shown in Table 8 and the data processed method, the emergy indices involved in the DEA assessment model are shown in Table 9.

Based on the data shown in Table 9, the DEA assessment methodology can be utilized to measure the sustainability 
TABLE 8: Emergy indices of various crops-based biodiesel.

\begin{tabular}{lccccc}
\hline Emergy indices & $\operatorname{Tr}(\mathrm{sej} / \mathrm{kg})$ & EYR & ELR & EIR & ESI \\
\hline Soybean & $9.95 E+12$ & 1.08 & 17.92 & 12.20 & 0.06 \\
Rapeseed & $9.18 E+12$ & 1.04 & 38.58 & 26.58 & 0.03 \\
Sunflower & $6.40 E+12$ & 1.07 & 22.60 & 14.41 & 0.05 \\
Palm & $5.83 E+12$ & 1.01 & 99.55 & 69.61 & 0.01 \\
Jatropha & $1.61 E+13$ & 1.006 & 244.68 & 171.08 & 0.004 \\
\hline
\end{tabular}

TABLE 9: The processed data of the inputs and outputs of DEA assessment system.

\begin{tabular}{lcccccc}
\hline \multirow{2}{*}{ Crop } & \multicolumn{3}{c}{ Inputs } & \multicolumn{3}{c}{ Outputs } \\
& Tr & ELR & EIR & ESI & EYR & P \\
\hline Soybean & 1.05 & 0.54 & 0.53 & 1.64 & 1.17 & 1.00 \\
Rapeseed & 0.97 & 1.71 & 1.71 & 0.37 & 0.83 & 1.00 \\
Sunflower & 0.67 & 0.71 & 0.69 & 1.13 & 1.06 & 1.00 \\
Palm & 0.61 & 1.45 & 1.52 & 0.44 & 0.85 & 1.00 \\
Jatropha & 1.70 & 0.59 & 0.56 & 1.41 & 1.09 & 1.00 \\
\hline
\end{tabular}

efficiency of each biodiesel production system; the calculating results including effective value, slack value and surplus value can be calculated, as shown in Table 10. According to Definitions 1 and 2, it can be summarized that the biodiesel production systems based on soybean, sunflower, and palm are DEA efficient, but the other two based on rapeseed or jatropha are non-DEA efficient.

Ye et al. had introduced a projection improvement analysis methodology to improve the non-DEA-efficient DMU to DEA efficient one [38]. Assume the optimal solution of linear programming (14) and (15) is $g^{j}, s_{r j}^{-}, s_{i j}^{+}$for DMU $j$ which is non-DEA-efficient, then the projection of the inputs and outputs on the relative efficient surface can be calculated using (18):

$$
\begin{gathered}
\hat{x}_{r j}=g^{j} x_{r j}-s_{r j}^{-} \\
\hat{y}_{i j}=y_{i j}+s_{i j}^{+},
\end{gathered}
$$

where $\hat{x}_{r j}$ and $\hat{y}_{i j}$ are the improved inputs and outputs, respectively.

From Table 10, it can be deduced that some of the inputs and outputs of the biodiesel production systems based on rapeseed and Jatropha should be improved to make them DEA efficient, the improvement results are calculated, as shown in Table 11, to rapeseed-based biodiesel production system, the emergy loading ratio should be reduced from 1.71 to 1.22 , and simultaneously, it is necessary to increase the emergy index of sustainability and emergy yield ratio from 0.37 to 0.74 and from 0.83 to 0.93 , respectively. Similarly, to jatropha-based biodiesel production system, some of the inputs, for instance, the transformity, emergy loading ratio and ecological footprint should be reduced from 1.70 to 1.05 , from 0.59 to 0.54 , and from 1.35 to 1.20 , respectively, simultaneously, it is necessary to increase the emergy index of sustainability and emergy yield ratio from 1.41 to 1.64 and from 1.09 to 1.17 , respectively. With these improvements,

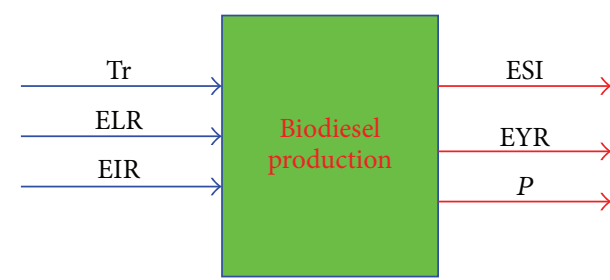

FIGURE 10: DEA assessment system for biodiesel production.

the rapeseed-based or jatropha-based biodiesel production system will be DEA efficient.

The sequence of the sustainability efficiency of the five kinds of crop-based biodiesel from the best to the worst is \{soybean-based, sunflower-based, palm-based\}, \{jatrophabased\}, and \{rapeseed-based\}.

\section{Results and Discussion}

Emergy analysis has the ability to integrate the environmental resources, purchased inputs, monetary, and labor into the generic indices of sustainability such as emergy index of sustainability and transformity.

Emergy analysis has been used to study the sustainability of soybean-, rapeseed-, sunflower-, jatropha- and palm-based biodiesel production options in this paper, the emergy indices of sustainability are $0.06,0.03,0.05,0.01$ and 0.004 , respectively. It can be recognized that soybean-based biodiesel is the most sustainable and none of the five options can be recognized as sustainable in long terms.

The economic inputs occupy the most part in the total solar joules of each crop-based biodiesel system, and the dependence on purchased resources reduces the fraction of renewable resources and increases the environmental loads. Therefore, developing new technologies to reduce the use of purchased resources and increase the use of renewable is the best way to achieve sustainable development of biodiesel.

The transformities of soybean-based, rapeseed-based, sunflower-based, palm-based, and jatropha-based biodiesel productions are calculated to be $9.85 E+12 \mathrm{sej} / \mathrm{kg}, 9.18 E+$ $12 \mathrm{sej} / \mathrm{kg}, 6.40 E+12 \mathrm{sej} / \mathrm{kg}, 5.83 E+12 \mathrm{sej} / \mathrm{kg}$, and $1.61 E+$ $13 \mathrm{sej} / \mathrm{kg}$, respectively. In the current situation, palm-based biodiesel is the most emergy-saving option. In order to decrease the transformities, improving the plantation technology to reduce the use of fertilizers and pesticide and to increase the yield of crops is urgently needed.

In order to compare the emergy indices comprehensively, DEA has been used to analyze the sustainability efficiency, the inputs comprise transformity (Tr), environmental loading ratio (ELR), and emergy investment ratio (EIR), the outputs include emergy sustainable index (ESI) emergy yield ratio (EYR) and product yield $(P)$. The biodiesel production system based on soybean, sunflower, and palm are DEA efficient, but the other two based on rapeseed or jatropha are non-DEA efficient.

Although soybean-, sunflower-, palm-based biodiesel options have been recognized as DEA efficient, due to the debate of "biodiesel versus food," if soybean and sunflower 
TABLE 10: The calculating results: effective value, slack value, and surplus value.

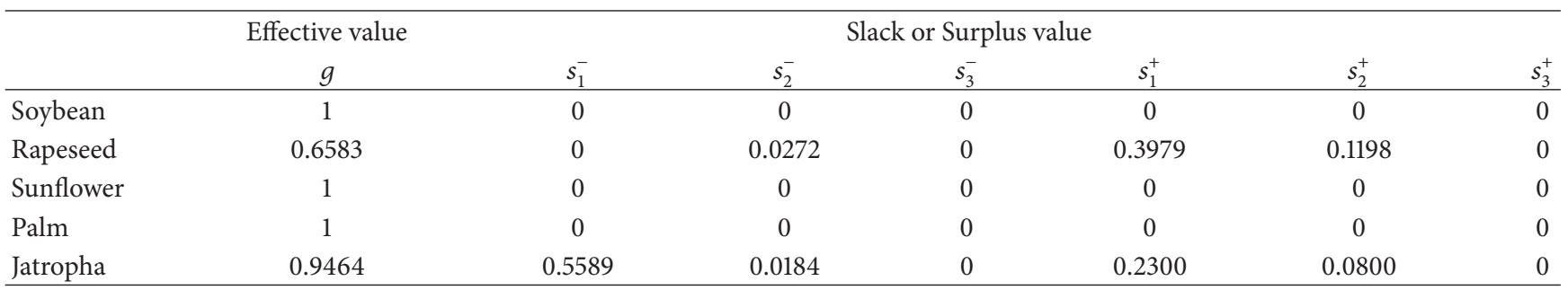

TABLE 11: Improved objective value of Non-DEA effective crop-based biodiesel system.

\begin{tabular}{lcccccccc}
\hline & \multicolumn{2}{c}{ Tr } & \multicolumn{2}{c}{ ELR } & \multicolumn{2}{c}{ ESI } & \multicolumn{2}{c}{ EYR } \\
& Actual & Improved & Actual & Improved & Actual & Improved & Actual & Improved \\
\hline Rapeseed & - & - & 1.71 & 1.0985 & 0.37 & 0.7679 & 0.83 & 0.9498 \\
Jatropha & 1.70 & 1.0500 & 0.59 & 0.5400 & 1.41 & 1.64 & 1.09 \\
\hline
\end{tabular}

are used to produce biodiesel, it may cause food crisis. From this point of view, palm is the most suitable to be chosen as the sustainability efficient option.

The authors calculate the emergy indices in an accurate and objective way, but there are also some drawbacks.

(i) The consistency of the data: the data about the energy consumption in each item and the transformity are cited from different published work, and some of the data has been adjusted.

(ii) The temporal and spatial consistency: the data used in emergy indices calculation are not obtained in the same time, and the cases studied have been assumed to locate in the same region.

The future work is to obtain high quality data and develop related method to verify the accuracy of the data.

\section{Conclusion}

Although biodiesel has been a hot spot since several decades ago and different scales of biodiesel plants have been operated around the world, the sustainability is not optimistic in the current situations. None of the options for biodiesel production is sustainable in a long term. In order to achieve high sustainability of biodiesel production, new plantation technologies to reduce the use of fertilizers and pesticide and to increase the yield of crops and novel methods to produce biodiesel with vegetables oil are prerequisite.

\section{References}

[1] H. C. Ong, T. M. I. Mahlia, H. H. Masjuki, and D. Honnery, "Life cycle cost and sensitivity analysis of palm biodiesel production," Fuel, vol. 98, pp. 131-139, 2012.

[2] E. Gnansounou, "Assessing the sustainability of biofuels: a logicbased model," Energy, vol. 36, no. 4, pp. 2089-2096, 2011.

[3] R. A. Diaz-Chavez, "Assessing biodiesel: aiming for sustainable development or complying with the market?" Energy Policy, vol. 39, no. 10, pp. 5763-5769, 2011.
[4] X. Xue, W. O. Collinge, S. C. Shrake, M. M. Bilec, and A. E. Landis, "Regional life cycle assessment of soybean derived biodiesel for transportation fleets," Energy Policy, vol. 48, pp. 295-303, 2012.

[5] H. Yang, L. Chen, Z. Yan, and H. Wang, "Emergy analysis of cassava-based fuel ethanol in China," Biomass and Bioenergy, vol. 35, no. 1, pp. 581-589, 2011.

[6] S. Y. Zhou, B. Zhang, and Z. F. Cai, "Emergy analysis of a farm biogas project in China: a biophysical perspective of agricultural ecological engineering," Communications in Nonlinear Science and Numerical Simulation, vol. 15, no. 5, pp. 1408-1418, 2010.

[7] S. Yang, F. Sun, B. Liu, Y. Du, and X. Li, "Energy analysis of agricultural eco-economic systems in Chongqing," Journal of Southwest University, vol. 29, no. 8, pp. 49-54 (Chinese).

[8] L. Ju, B. Chen, Z. Yang et al., "Emergy analysis for the whole biodiesel production process with jatropha curcas oil as raw materials," Acta Ecologica Sinica, vol. 30, no. 20, pp. 5646-5652, 2010 (Chinese).

[9] S. Liu and D. Sun, "Emergy evaluation of a kind of biodiesel production system and construction of new emergy indices," Journal of Nanjing University (Natural Sciences), vol. 43, no. 2, pp. 111-118, 2007 (Chinese).

[10] S. F. Lan, P. Qin, and H. F. Lu, Emergy Analysis of Eco-Economic System, Chemical Industry Press, Beijing, China, 2002.

[11] Z. Zhou, H. Jiang, and L. Qin, "Life cycle sustainability assessment of fuels," Fuel, vol. 86, no. 1-2, pp. 256-263, 2007.

[12] J. Hou, P. Zhang, X. Yuan, and Y. Zheng, "Life cycle assessment of biodiesel from soybean, jatropha and microalgae in China conditions," Renewable and Sustainable Energy Reviews, vol. 15, no. 9, pp. 5081-5091, 2011.

[13] S. Kim and B. E. Dale, "Life cycle assessment of various cropping systems utilized for producing biofuels: bioethanol and biodiesel," Biomass and Bioenergy, vol. 29, no. 6, pp. 426439, 2005.

[14] L. Panichelli, A. Dauriat, and E. Gnansounou, "Life cycle assessment of soybean-based biodiesel in Argentina for export," International Journal of Life Cycle Assessment, vol. 14, no. 2, pp. 144-159, 2009.

[15] C. Nzila, J. Dewulf, H. Spanjers, D. Tuigong, H. Kiriamiti, and H. Langenhove, "Multi criteria sustainability assessment of biogas production in Kenya," Applied Energy, vol. 93, pp. 496506, 2012. 
[16] J. A. Scott, W. Ho, and P. K. Dey, "A review of multi-criteria decision-making methods for bioenergy systems," Energy, vol. 42, pp. 146-156, 2012.

[17] H. Safaei Mohamadabadi, G. Tichkowsky, and A. Kumar, "Development of a multi-criteria assessment model for ranking of renewable and non-renewable transportation fuel vehicles," Energy, vol. 34, no. 1, pp. 112-125, 2009.

[18] G. Stoeglehner and M. Narodoslawsky, "How sustainable are biofuels? Answers and further questions arising from an ecological footprint perspective," Bioresource Technology, vol. 100, no. 16, pp. 3825-3830, 2009.

[19] L. P. Ju and B. Chen, "Embodied energy and emergy evaluation of a typical biodiesel production chain in China," Ecological Modelling, vol. 222, no. 14, pp. 2385-2392, 2011.

[20] O. Cavalett and E. Ortega, "Integrated environmental assessment of biodiesel production from soybean in Brazil," Journal of Cleaner Production, vol. 18, no. 1, pp. 55-70, 2010.

[21] F. Takahashi and E. Ortega, "Assessing the sustainability of Brazilian oleaginous crops-possible raw material to produce biodiesel," Energy Policy, vol. 38, no. 5, pp. 2446-2454, 2010.

[22] H. T. Odum, Environmental Accounting: Emergy and Environmental Decision Making, John Wiley \& Sons, New York, NY, USA, 1995.

[23] B. F. Giannetti, F. A. Barrella, and C. M. V. B. Almeida, "A combined tool for environmental scientists and decision makers: ternary diagrams and emergy accounting," Journal of Cleaner Production, vol. 14, no. 2, pp. 201-210, 2006.

[24] M. T. Brown and S. Ulgiati, "Emergy evaluations and environmental loading of electricity production systems," Journal of Cleaner Production, vol. 10, no. 4, pp. 321-334, 2002.

[25] G. Zhang and W. Long, "A key review on emergy analysis and assessment of biomass resources for a sustainable future," Energy Policy, vol. 38, no. 6, pp. 2948-2955, 2010.

[26] C. M. V. B. Almeida, F. A. Barrella, and B. F. Giannetti, "Emergetic ternary diagrams: five examples for application in environmental accounting for decision-making," Journal of Cleaner Production, vol. 15, no. 1, pp. 63-74, 2007.

[27] T. Tsoutsos, V. Kouloumpis, T. Zafiris, and S. Foteinis, "Life cycle assessment for biodiesel production under Greek climate conditions," Journal of Cleaner Production, vol. 18, no. 4, pp. 328-335, 2010.

[28] J. Zhang, Z. Tang, and H. Zhou, "The costs and benefits analysis of soybean in Heilongjiang," Grain Economy Forum, vol. 6, pp. 45-48, 2009 (Chinese).

[29] K. F. Yee, K. T. Tan, A. Z. Abdullah, and K. T. Lee, "Life cycle assessment of palm biodiesel: revealing facts and benefits for sustainability," Applied Energy, vol. 86, no. 1, pp. S189-S196, 2009.

[30] W. M. J. Achten, P. Vandenbempt, J. Almeida, E. Mathijs, and B. Muys, "Life cycle assessment of a palm oil system with simultaneous production of biodiesel and cooking oil in Cameroon," Environmental Science \& Technology, vol. 44, no. 12, pp. 4809-4815, 2010.

[31] S. Papong, T. Chom-In, S. Noksa-nga, and P. Malakul, "Life cycle energy efficiency and potentials of biodiesel production from palm oil in Thailand," Energy Policy, vol. 38, no. 1, pp. 226$233,2010$.

[32] A. H. Xing, J. Ma, Y. H. Zhang, Y. Wang, and Y. Jin, "Life cycle assessment of resource and energy consumption for production of biodiesel," The Chinese Journal of Process Engineering, vol. 10, no. 2, pp. 314-320, 2010 (Chinese).
[33] P. K. Sahoo and L. M. Das, "Process optimization for biodiesel production from Jatropha, Karanja and Polanga oils," Fuel, vol. 88, no. 9, pp. 1588-1594, 2009.

[34] A. Charnes, W. W. Cooper, and E. Rhodes, "Measuring the efficiency of decision making units," European Journal of Operational Research, vol. 2, no. 6, pp. 429-444, 1978.

[35] T. A. Chiang and Z. H. Che, "A fuzzy robust evaluation model for selecting and ranking NPD projects using Bayesian belief network and weight-restricted DEA," Expert Systems with Applications, vol. 37, no. 11, pp. 7408-7418, 2010.

[36] A. Basso and S. Funari, "A data envelopment analysis approach to measure the mutual fund performance," European Journal of Operational Research, vol. 135, no. 3, pp. 477-492, 2001.

[37] A. Sözen, I. Alp, and A. Özdemir, "Assessment of operational and environmental performance of the thermal power plants in Turkey by using data envelopment analysis," Energy Policy, vol. 38, no. 10, pp. 6194-6203, 2010.

[38] Y. C. Ye, H. L. Ke, and D. Y. Huang, System Synthetical Evaluation Technology and Its Application, Matellurgical Industry Press, Beijing, China, 1st edition, 2006. 

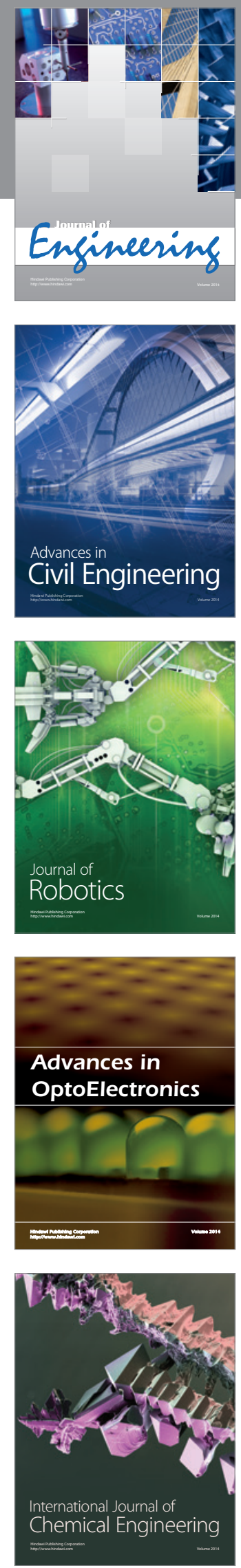

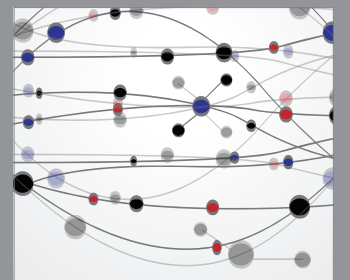

The Scientific World Journal
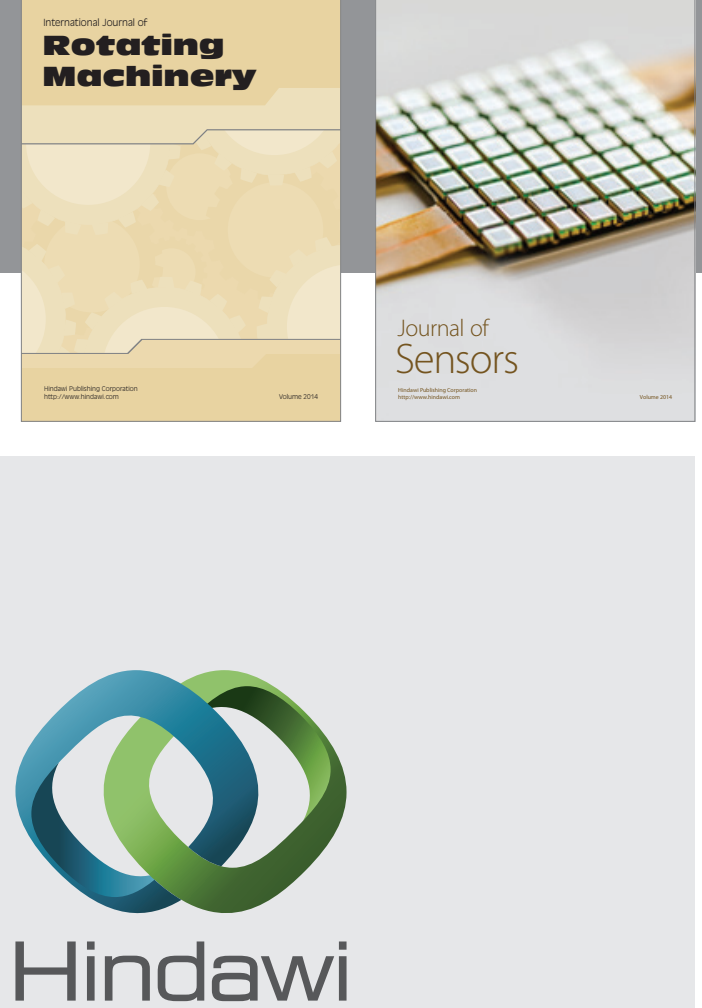

Submit your manuscripts at http://www.hindawi.com
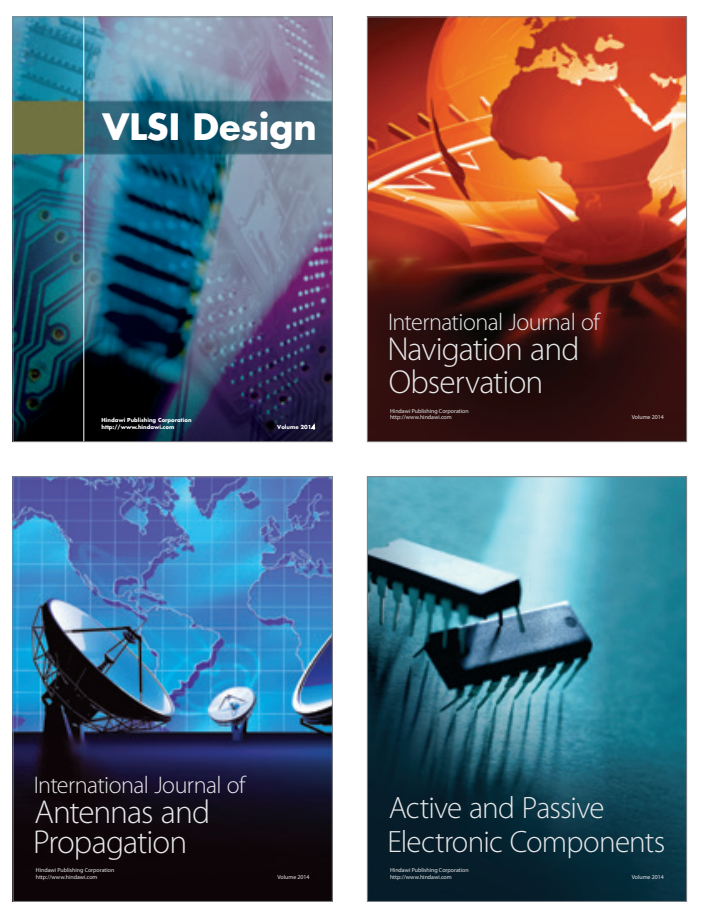
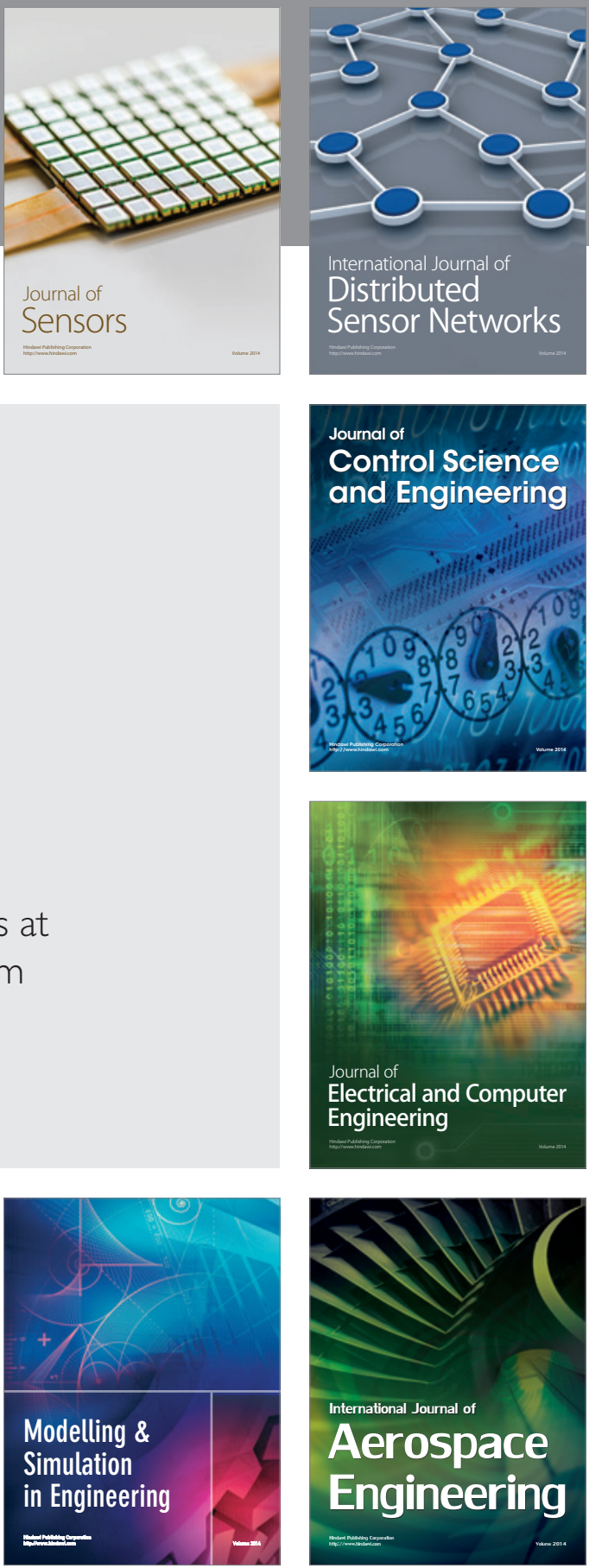

Journal of

Control Science

and Engineering
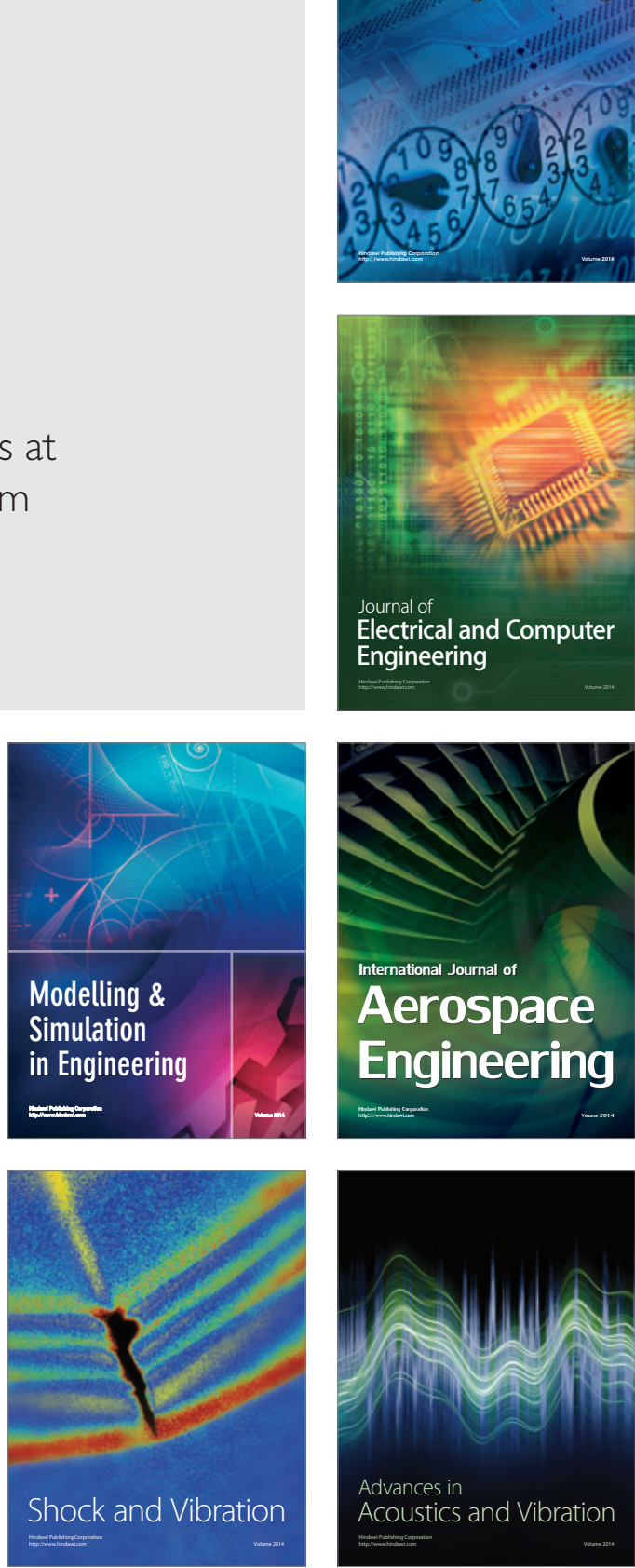